\title{
Highly Efficient Glass Ceramic Thermal Insulation
}

\author{
Ivan Vedyakov, Vladimir Vaskalov, Nikolai Maliavski ${ }^{*}$, and Mikhail Vedyakov \\ V. A. Kucherenko Central Research Institute for Building Structures (TSNIISK), 109428, $2^{\text {nd }}$ \\ Institutskaya St., 6, Moscow, Russia
}

\begin{abstract}
Alkali-silicate thermal insulation materials (foam silicates) belong to the group of mineral heat insulators. Their main disadvantage is insufficient water resistance, to increase which special water-strengthening additives are introduced into materials. The aim of this work was to obtain and study foam silicates in granular (FGCG) and slab (FGCS) forms using a new production technology characterized by a simple one-stage technological scheme. Natural or technogenic amorphous silica, glassy sodium silicate (with the addition of carbonate or hydroxide) and a carboncontaining foaming agent, were used as the raw materials. Some part of the silica component was included in the binder solution, which made it possible to increase the silicate modulus in the final product to 5-10. This factor together with rather high $\mathrm{Al}_{2} \mathrm{O}_{3}$ concentration in the silica raw, made it possible to obtain foamed materials of very high water resistance. Another feature of the applied technology was a high foaming temperature $\left(750-900^{\circ} \mathrm{C}\right)$. This factor makes a significant contribution to improving the water resistance of foam silicates, and significantly reducing their thermal conductivity and water absorption. As a result, FGCG was obtained with a bulk density of $170-440 \mathrm{~kg} / \mathrm{m}^{3}$ (for FGCS $-300-400 \mathrm{~kg} / \mathrm{m}^{3}$ ), a compressive strength in a cylinder of $0.5-6.3 \mathrm{MPa}$, a thermal conductivity of 0.046 $0.084 \mathrm{~W} /(\mathrm{m} \cdot \mathrm{K})$ and a water absorption of $7.8-13.5 \%$ by volume. Mass loss of the specimens in boiling water was $0.12-0.33 \%$, which puts obtained foamed materials on a par with most waterproof foam silicates being produced today.
\end{abstract}

\section{Introduction}

Energy saving measures in modern construction are mainly aimed at saving heat. This explains the constant growth in the demand for thermal insulation materials (TIM) and the intensification of research and development to improve energy efficiency and other consumer properties of such materials.

In the past few decades, the interest of manufacturers in inorganic thermal insulation materials that combine low thermal conductivity with durability, wear resistance, biostability, heat resistance and incombustibility, has grown significantly. Worthy among such materials occupy alkali-silicate foamed materials (foam silicates) obtained by cold or

${ }^{*}$ Corresponding author: nikmal08@yandex.ru 
hot foaming solutions or hydrogels of alkaline silicates, usually sodium or potassium silicates. The advantages of foam silicates in comparison with other inorganic TIMs, are the attainability of relatively low values of density and thermal conductivity (respectively, 60 $\mathrm{kg} / \mathrm{m}^{2}$ and $0.03 \mathrm{~W} /(\mathrm{m} \cdot \mathrm{K})$ ) and easy controllability of foaming and curing processes.

The simplest way to obtain a solid foamed material of alkaline-silicate hydrogel (dried water glass) can be realized by heating above $150-200^{\circ} \mathrm{C}$. Foaming agent in this case is chemically bound water (mainly silanol or molecular, strongly bound by hydrogen bonds with the unbridged oxygen atoms) in the composition of the hydrogel $[1,2]$. A mathematical model of this process was proposed several years ago in [3]. Unfortunately such a foamed material is absolutely not water-resistant and cannot be used in constructions. To improve its water resistance, three chemical modification methods are commonly used.

The first method is associated with an increase in the silicate modulus which in ordinary water glass does not exceed 3.0-3.5. This can be accomplished by partial binding of the alkaline component by reaction with additives of an acid nature $\left(\mathrm{CO}_{2}, \mathrm{SiO}_{2} \cdot \mathrm{xH}_{2} \mathrm{O}, \mathrm{H}_{3} \mathrm{BO}_{3}\right)$, the same binding with simultaneous addition of silica component (additives of $\mathrm{Na}_{2} \mathrm{SiF}_{6}$ type), extraction of the alkaline component by electrodialysis and other methods [1].

The second method consists in introducing additional glass-forming oxides $\left(\mathrm{B}_{2} \mathrm{O}_{3}\right.$, $\mathrm{Al}_{2} \mathrm{O}_{3}, \mathrm{ZnO}$ ) into water glass or alkaline silicate hydrogel; $\mathrm{B}, \mathrm{Al}$ or $\mathrm{Zn}$ atoms chemically bind the alkaline oxide and prevent its release from the foam material into the aqueous phase [4-6]. Finally, the third method, used mainly in cold foaming of water glass, consists in transferring, already at the hydrogel stage, a significant part of the silicate from a watersoluble form to a water-insoluble one by introducing into the water glass poorly soluble calcium compounds (oxide, hydroxide or highly basic silicate) [7].

Some of the foam silicates obtained by these methods, such as "Evolit-thermo" [8] and "Paroglass ETIZ" [7], have been successfully produced in slab and block forms. But usually, the preferred production form of alkali-silicate insulation is the form of granules which providing a more uniform material and a better control of its physical and chemical parameters. The most mechanically and chemically durable granules obtained from such methods, have been proposed as fillers of lightweight concretes as an alternative to more expensive perlite and foam glass fillers. Such a substitution appears all the more possible and desirable, because the technology and production of perlite- and foam-glass-containing concretes developed in great detail and there have an understanding dependence of the final material properties on process parameters [9-12].

In 2006, a report appeared in the scientific literature about the possibility of obtaining foam silicate of increased strength and water resistance from natural amorphous silica using high-temperature foaming of raw granules obtained by a one-stage technology [13]. Subsequently, this possibility was confirmed by patents: in 2014 - for the manufacture of foam silicate blocks [14], and in 2017 - for the manufacture of granular foam silicate using a similar technology [15].

The purpose of these inventions was to dramatically improve the quality (increase in mechanical strength and water resistance, decrease in water absorption) of the foam silicate by significantly increasing the foaming temperature from $350-550$ to $700-900^{\circ} \mathrm{C}$ and changing the type of foaming agent (an external carbon-containing foaming agent instead of hydrosilicate water). The main feature of the new technology was the rejection of the use of ready-made water glass and the synthesis of a binder solution directly during the preparatory stage of the process from anhydrous sodium silicate, amorphous silica and water (in the variant [15] - also $\mathrm{Na}_{2} \mathrm{CO}_{3}$ ). Natural amorphous silica served as the basis for the silica component of the raw mixture. The ratio of the components of the raw mixture was selected so that in the final product the silicate modulus was very high: 5-7 and higher with acceptable rheological parameters of the binder solution. Foaming was carried out in a 
vertical furnace at $700-900^{\circ} \mathrm{C}$, the result was obtaining microgranules having a bulk density of $150-240 \mathrm{~kg} / \mathrm{m}^{3}$, water absorption $0.8-4.6 \%$ (in block form, respectively, $210 \mathrm{~kg} / \mathrm{m}^{3}$ and $2 \%$ ) and closed porosity.

One more direction stands out in the array of studies on foam silicates - ecological. It is about finding opportunities to use industrial waste in raw mixes instead of natural minerals and rocks. The topics of most of these works based on the objects and methods of researches, can reasonably be attributed to chemistry and materials science of geopolymers - natural or man-made binders of silicate and aluminosilicate nature, capable of alkali activation [16]. With regard to foam silicates, it is about studies of the possibility of using industrial waste as a silicate component [17-19]. The main result of such researches is not so much a price reduction or achievement of a technical effect, but rather a contribution to solving the problem of waste disposal.

The main goal of this work is to analyze the chemical composition and physical and technical properties of foam silicate samples obtained at a semi-industrial plant using the technology patented in $[14,15]$. We will also describe the first results of the analysis of a system in which a naturally occurring siliceous component was replaced by waste from the production of phosphorus fertilizers.

\section{Experimental}

Samples of glass ceramic foam insulation were made in the form of slabs (FGCS) and granules (FGCG). Overall apparent density values for FGCS samples was determined according to GOST EN 1602-2011, the bulk density of the FGCG samples - according to GOST $9758-2012$.

The compressive strength of the FGCS samples was determined according to GOST EN 826-2011, the compressive strength of the FGCG samples when squeezed in the cylinder to GOST $32495-2013$.

Thermal conductivity coefficient of FGCS samples was determined according to GOST 33949-2016, the same of the FGCG samples in the backfill - according to GOST 324972013.

Water resistance of FGCG and FGCS samples was assessed by the percentage of weight loss as a result of boiling in water according to GOST 32496-2013.

Water absorption and frost resistance of FGCG and FGCS samples were determined according to GOST 9758-2012.

The concentration of volatile components (mainly $\mathrm{H}_{2} \mathrm{O}$ and $\mathrm{CO}_{2}$ ) in FGCG and FGCS samples was determined by thermogravimetry using a SDT Q 600 thermal analyzer (TA Instruments).

Chemical analysis of the siliceous components of the raw materials was carried out by atomic emission spectrometry using an iCAP- 6200 Duo inductively coupled plasma spectrometer (Thermo Scientific), according to GOST R 57165-2016. The dissolution of samples was carried out by 1 -day exposure to $45 \%$ HF in a tightly closed Teflon container, followed by rapid 50 -fold dilution with distilled water

\section{Results}

Samples for researches were obtained using an experimental plant for the production of porous fillers for lightweight concretes, operating at TSNIISK (Figure 1). The sources for obtaining the siliceous components of the raw mixture were: diatomite of the Inza deposit (Ulyanovsk region), tripoli from the Khotynets deposit (Oryol region) and technogenic raw 
material AFT - apatite flotation tailings from Kirovsk (Murmansk region). The chemical compositions of the siliceous components of the raw materials, are presented in Table 1.

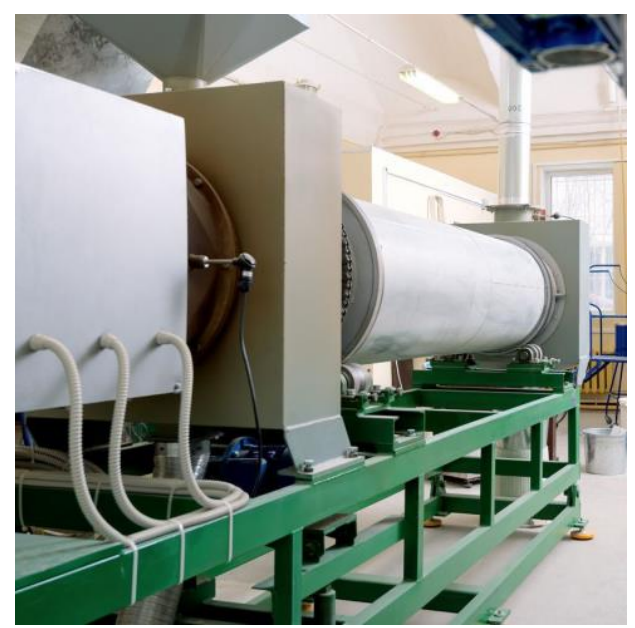

Fig. 1. General appearance of the pilot plant for the FGCG production:

Table 1. Chemical composition of used siliceous components of raw mixtures

\begin{tabular}{|c|c|c|c|}
\hline \multirow{2}{*}{ Components } & \multicolumn{3}{|c|}{ Content in mass\% } \\
\cline { 2 - 4 } & Diatomite & Tripoli & ATF \\
\hline $\mathrm{SiO}_{2}$ & 77.5 & 71.3 & 63.3 \\
\hline $\mathrm{Al}_{2} \mathrm{O}_{3}$ & 10.3 & 6.7 & 12.1 \\
\hline $\mathrm{Fe}_{2} \mathrm{O}_{3}$ & 2.8 & 2.6 & 4.0 \\
\hline $\mathrm{MgO}$ & 0.2 & 1.7 & 0.9 \\
\hline $\mathrm{CaO}$ & 0.4 & 2.4 & 1.9 \\
\hline $\mathrm{Na}_{2} \mathrm{O}$ & 0.6 & 0.4 & 8.1 \\
\hline $\mathrm{K}_{2} \mathrm{O}$ & 0.8 & 1.8 & 3.5 \\
\hline $\mathrm{SO}_{3}$ & 0.1 & 0.7 & 0.2 \\
\hline $\mathrm{P}_{2} \mathrm{O}_{5}$ & 0.1 & 0.7 & 2.4 \\
\hline $\mathrm{Loss}_{5}$ ignition & 3.0 & 6.5 & 1.1 \\
\hline$\left[\mathrm{SiO}_{2}\right] /\left(\left[\mathrm{Na}_{2} \mathrm{O}\right]+\left[\mathrm{K}_{2} \mathrm{O}\right]\right)$ & 46.4 & 46.4 & 6.3 \\
\hline$\left[\mathrm{Al}_{2} \mathrm{O}_{3}\right] /\left[\mathrm{SiO}_{2}\right]$ & 0.078 & 0.055 & 0.112 \\
\hline
\end{tabular}

The technology for obtaining glass-ceramic foams (FGCG or FGCS) includes the following main operations:

- preparation of the siliceous component (crushing, drying, grinding);

- preparation of the binder solution by wet grinding at $80-100^{\circ} \mathrm{C}$ soluble glass together with the foaming agent and a part of the siliceous component;

- mixing the metered amounts of the binding solution and the siliceous component to obtain a plastic mass with a viscosity optimal for granulation by extrusion or tableting at the outlet of the mixer;

- drying of granules at $200^{\circ} \mathrm{C}$ to obtain an intermediate product - green granulate;

- in the FGCG version: foaming the green granulate in a rotating drum oven at 750 $900^{\circ} \mathrm{C}$ with subsequent cooling and sieving;

- in the FGCS version: foaming the green granulate placed in a closed metal mold, by heating at a rate of $10^{\circ} \mathrm{C} / \mathrm{min}$. up to $760^{\circ} \mathrm{C}$ with subsequent cooling according to a special mode. 
A block-chart of the FGCG production technology is shown in Figure 2.

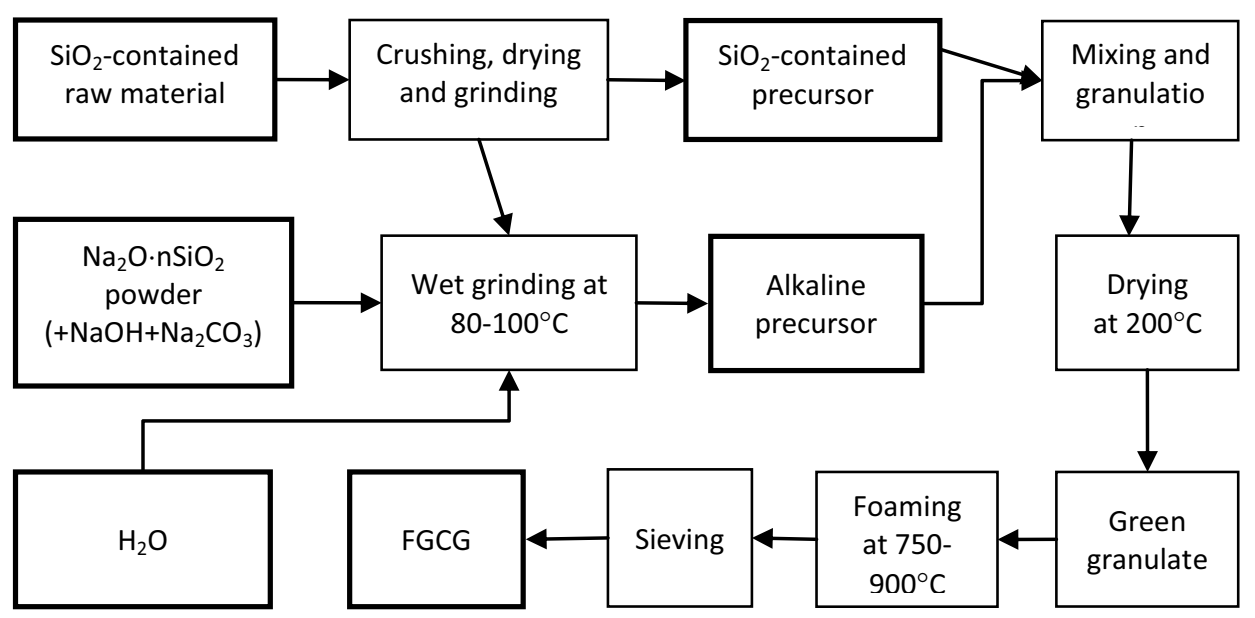

Fig.2. Flow-chart of the FGCG production

The main distinguishing features of the foam silicate production technology are:

- branching of the technological path of the silica-containing component after the first group of technical operations (a smaller part is involved in the preparation of the binder solution, most of it subsequently interacts with the solution to form a granular mass);

- high temperature of final foaming (open pores are formed at $150-550^{\circ} \mathrm{C}$ due to the released water vapor, when the temperature reaches $750^{\circ} \mathrm{C}$ they close, and above this temperature new closed pores are formed under the action of the foaming agent).

The result of the process shown in Figure 2, is an FGCG granulate which has a complex of valuable physical, mechanical and chemical properties listed in Table 2.

Table 2. Key performance properties of FGCG obtained using Inza diatomite

\begin{tabular}{|c|c|c|c|}
\hline $\begin{array}{l}\text { Item } \\
\text { No. }\end{array}$ & Properties & Units & Range of values \\
\hline 1 & $\begin{array}{l}\text { Grading: } \\
\text { Fraction } 5.0-20.0 \mathrm{~mm} \\
\text { Fraction } 2.5-5.0 \mathrm{~mm} \\
\text { Fraction } 1.25-2.5 \mathrm{~mm} \\
\text { Fraction } 0-1.25 \mathrm{~mm}\end{array}$ & $\begin{array}{l}\text { mass } \% \\
\text { mass } \% \\
\text { mass } \% \\
\text { mass } \%\end{array}$ & $\begin{array}{c}5-10 \\
80-90 \\
5-10 \\
0-5\end{array}$ \\
\hline 2 & Bulk density & $\mathrm{kg} / \mathrm{m}^{3}$ & $170-440$ \\
\hline 3 & $\begin{array}{l}\text { Compressive strength under compression in a } \\
\text { cylinder }\end{array}$ & $\mathrm{MPa}$ & $0.5-6.3$ \\
\hline 4 & Thermal conductivity in the backfill & $\mathrm{W} /(\mathrm{m} \cdot \mathrm{K})$ & $0.046-0.084$ \\
\hline 5 & Mass loss when boiled in water & mass $\%$ & $0.27-0.33$ \\
\hline 6 & Volumetric water absorption & vol. \% & $7.8-13.5$ \\
\hline 7 & Frost resistance & Grade & F25 \\
\hline
\end{tabular}

We also analyzed the dependences on granulate bulk densities of two important characteristics: the compressive strength under compression in a cylinder and the thermal conductivity in the backfill. The values of these parameters were measured for twelve narrow FGCG fractions in air-dry state. Graphs of correspondent approximations (in the first case - exponential, in the second one - linear [20]) are shown in Figure 3. Approximating functions are as follows: 


$$
\begin{gathered}
R=0.1514 e^{0.0083 \rho} \\
\lambda=0.0001452 \rho-0.0225
\end{gathered}
$$

Comparison of obtained materials for water resistance showed that water resistance moderately depends on the type of siliceous component. Table 3 shows the experimentally found values of mass loss during boiling $(h)$ together with data for ignition loss $(w)$ and total apparent density $(\rho)$ for two samples of granulate and two samples of slab material made using three siliceous components: diatomite, tripoli and AFT. The values of $h$ for different samples differ by a maximum of 3-4 times, but generally remain within the same order of magnitude.

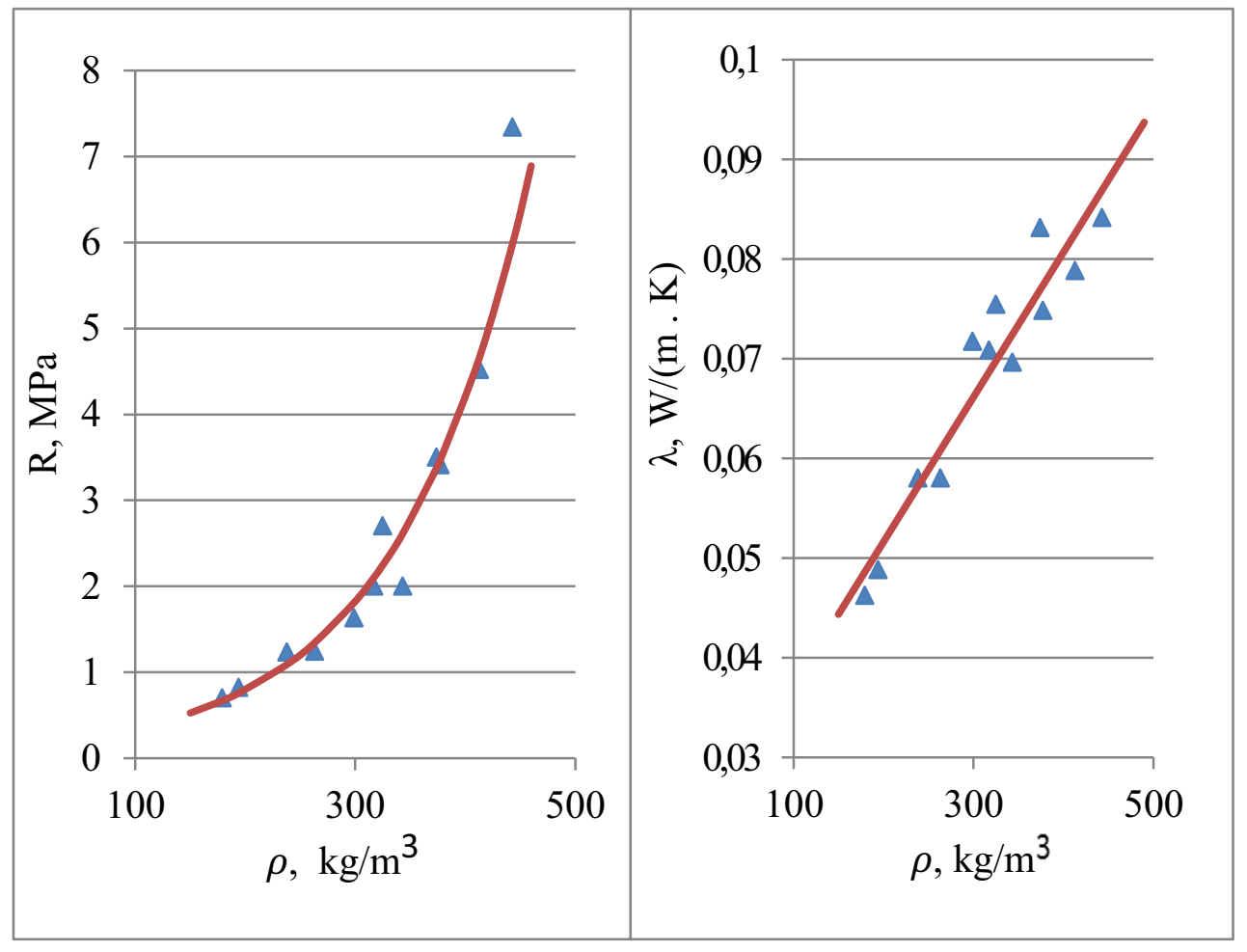

a

b

Fig. 3. Dependencies on FGCG bulk density:

$\mathrm{a}$ - of compressive strength in a cylinder $(R) \mathrm{b}$ - of thermal conductivity in backfill $(\lambda)$

Table 3. Characteristics of water resistance for foam silicate samples

\begin{tabular}{|c|c|c|c|c|c|c|}
\hline Item No. & $\begin{array}{c}\text { Sample } \\
\text { types }\end{array}$ & $\begin{array}{c}\mathrm{SiO}_{2^{-}} \\
\text {component }\end{array}$ & $w . \%$ & $\rho . \mathrm{kg} / \mathrm{m}^{3}$ & $h . \%$ & $H . \mathrm{kg} / \mathrm{m}^{3}$ \\
\hline 1 & FGCG & Diatomite & 0.37 & 483 & 0.33 & 1.59 \\
\hline 2 & FGCS & Diatomite & 0.20 & 395 & 0.31 & 1.22 \\
\hline 3 & FGCS & Tripoli & 0.83 & 294 & 0.22 & 0.64 \\
\hline 4 & FGCG & ATF & 0.46 & 344 & 0.12 & 0.41 \\
\hline
\end{tabular}


In the last column of the Table 3, the calculated values of the effective water resistance $H$ are given, which allows comparing the water resistance

$$
H=0.01 \rho h\left(1-\frac{w}{100}\right)
$$

For the most water resistant foam materials, $H$ is less than 3.0. Values of $3.0<H<10.0$ are considered acceptable for non-extreme conditions. The values of $H$ given in table 3 indicate that the obtained FGCG and FGCS belong to alkali-silicate insulators with the highest water resistance, such as (in parentheses $-H$ values): Steklopor and Bisipor (1-2) Aerosteklo (0.6-4), Kremnezit (1.5-2.5).

\section{Discussion}

The above-described technology for producing foam silicate is an alternative to the twostage technology for producing foam glass from cullet and glass production waste. Highly active components (cristobalite, opal, hydrated and amorphous silica) contained in raw materials, can actively react with alkaline solutions and are able to participate in silicate formation reactions at not too high temperatures. The use of siliceous rocks with an increased (up to $10 \%$ ) content of $\mathrm{Al}_{2} \mathrm{O}_{3}$ and reduced content of alkaline-earth oxides, significantly increases the water resistance of foam silicate in an alkaline medium and reduces the coefficient of its thermal linear expansion. This significantly simplifies the production of foam silicates and improves product performance.

Furthermore, alkali-silicate binder solution is capable of reacting with highly dispersed opal and cristobalite in a wide temperature range to form a low melting glass phase, providing early formation of closed cell structure and, consequently, a decrease in the thermal conductivity and water absorption of the final material. This also makes it possible to reduce the total content of $\mathrm{Na}_{2} \mathrm{O}$ in the system to $10-12$ wt.\%, i.e. to the minimum required for the formation of a closed cell structure. Due to this, the water resistance of foam silicates is significantly increased.

But the main reason for the high water resistance of the obtained foam silicates is the increased chemical resistance of the outer shell of the granules and the walls of the inner pores. This is facilitated by two factors: an increased silicate modulus and an increased content of glass-forming oxides (in this case, $\mathrm{Al}_{2} \mathrm{O}_{3}$ ). In particular, among the foam silicates listed in table. 3 , the high water resistance of sample No. 3 is explained by the first factor, sample No. 4 - by the second factor, samples No. 1 and No. 2 - by both factors.

In continuation of the described studies, the developed technology was used to obtain and study of foams based on other types of siliceous components: diatomites and tripolis from other deposits, flask, zeolites and volcanic ash. In all cases after a certain optimization of the technology for a specific type of system, foam silicates with properties close to those indicated above, were obtained.

As follows from the presented here indicators, FGCG and FGCS can be successfully used as fillings insulation in buildings and structures, for the manufacture of rigid plate heat insulation, both independently and as a part of especially lightweight concrete with a density of $300-700 \mathrm{~kg} / \mathrm{m}^{3}$. This concrete can be used for the production of single-layer wall panels, large and small blocks, as well as for the construction of monolithic walls, ceilings and floors in removable and non-removable formwork. 


\section{Conclusions}

Alkaline-silicate thermal insulating materials are increasingly used in industrial and civil construction. This is largely due to their important advantages over other mineral heat insulators, such as the ability to achieve minimum density and thermal conductivity, ease of adjusting material parameters, low cost and widespread availability of raw materials.

For use in construction, a new foamed glass-ceramic insulation is proposed in the form of granulate (FGCG) and slabs (FGCS), the raw material for which are a silica component (amorphous silica of natural or technogenic origin), an alkaline component (sodium silicate, carbonate or hydroxide ) and a carbon-containing foaming agent. Its production process is distinguished by a simple one-stage scheme and elevated foaming temperature (750$\left.900^{\circ} \mathrm{C}\right)$.

The resulting silicate foam material is characterized by increased strength, high water resistance, and reduced water absorption. The combination of closed porosity, high silicate modulus and increased alumina content places the obtained materials in a range of alkalisilicate heat insulators with the highest water resistance.

\section{References}

1. V.I. Korneev, V.V. Danilov, Soluble and water glass (Ed. Stroyizdat, 1996, in Russian)

2. N.I. Maliavski, Rus. Chem. J., 47 (4), 39-45, (2003, in Russian)

3. A. Pavlenko, H. Koshlak, Metallurg. Min. Ind., 7, 118-122 (2015)

4. B.V. Generalov, O.V. Krifuks, N.I. Maliavski, Constr. Mater. Rus., No. 1, 7-8 (1999, in Russian)

5. N.I. Maliavski, B.V. Pokidko, V.A. Gevorkyan, Roof. Insul. Mater., No. 1, 28-30 (2007, in Russian)

6. S. Mizuryaev, A. Chiknovoryan, G. Solopova, MATEC Web Conf., 86, 04012 (2016)

7. N.I. Maliavski, V.V. Zvereva, VolgGASU Internet Bull., 2 (38) (2015, in Russian)

8. V.F. Korovyakov, Constr. Mater. Rus., No. 3, 14-15 (2003, in Russian)

9. L.V. Alekseeva, Constr. Mater. Rus., No. 6, 74-77 (2006, in Russian)

10. Y.I. Berov, S.I. Petrov, P.G. Dudko, V.V. Nasedkin, Constr. Mater. Rus., No. 6, 82-83 (2006, in Russian)

11. V.V. Nasedkin, Constr. Mater. Rus., No. 6, 70-73 (2006, in Russian)

12. A.N. Davidyuk, V.I. Savin, T.A. Kuzmitch, V.N. Strotskiy, A.A. Davidyuk, Ind. Civil Constr., No. 4, 56-64 (2018, in Russian)

13. A.D. Orlov, Constr. Mater. Rus., No. 1, 24-26 (2006, in Russian)

14. V. Vaskalov, A. Orlov, I. Vedyakov, RF Pat. 2513807 (2014)

15. V. Vaskalov, I. Vedyakov, A. Nezhikov, A.D. Orlov, RF Pat. 2605982 (2017)

16. J. Davidovits, 2011 Geopolymer chemistry \& applications, 3rd Ed., (Ed. Geopolymer Institute, Saint-Quentin, 2011)

17. E.P. Kearsley, P.J. Wainwright, Cem. Concr. Res., 31, 105-112 (2001)

18. R. Dachowski, P. Kostrzewa, Proc. Eng., 161, 754-758 (2016)

19. A. Pavlenko, A. Szkarowski, Srod.-Pom. Roczn. Ochr. Srod., 20, 725-740, (2018)

20. B.K. Demidovich, Foam glass (Ed. Science and Technology, 1975, in Russian) 